\title{
Urethral syndrome in women attending a clinic for sexually transmitted diseases
}

\author{
SANAT K PANJA \\ From the Department of Genitourinary Medicine, Royal Infirmary, Cardiff
}

SUMMARY Of 107 women investigated for frequency of micturition and dysuria, 21 had gonorrhoea, 14 chlamydial urethritis, eight an Escherichia coli urinary tract infection, 18 candidosis, 12 trichomoniasis, and four asymptomatic genital herpes. No organisms were isolated from 30 patients. Eighty nine women referred themselves and 18 were referred by the family practitioner.

These findings suggest that Chlamydia trachomatis is frequently associated with the urethral syndrome among patients attending sexually transmitted disease clinics.

\section{Introduction}

Frequency of micturition and dysuria are common complaints in women. In the United Kingdom its prevalence in women aged 21-65 years is 22\%. ${ }^{1}$ In the United States lower urinary tract infection accounts for at least five million medical consultations every year. ${ }^{2}$ As many as $30 \%$ of these patients have sterile urine. ${ }^{34}$ Most studies of the urethral syndrome have been carried out in general practice. More recently Chlamydia trachomatis has been found to be an important cause of the urethral syndrome. ${ }^{56}$ Chlamydial infection is responsible for many cases of urethral syndrome in the absence of infection with conventional urinary pathogens. ${ }^{7}$ Asymptomatic genital herpes is becoming a common cause of frequency and dysuria among patients attending sexually transmitted disease clinics. ${ }^{8}$

The aim of this study was to determine which organisms were associated with the urethral syndrome and to assess the response to treatment.

\section{Patients and methods}

One hundred and seven women who attended the department of genitourinary medicine at the Royal Infirmary, Cardiff, with complaints of frequency of micturition and dysuria were studied. Eighty nine patients attended because they thought they might

Address for reprints: Dr S K Panja, Department of Genitourinary Medicine, Cardiff Royal Infirmary, Newport Road, Cardiff CF2 1SZ

Accepted for publication 24 November 1982 have contracted a sexually transmitted disease; 18 were referred by the family practitioner because of recurrent episodes of frequency and dysuria. Patients with ulceration of the vulva or vagina or genital warts were excluded from the study. After careful clinical examination specimens were taken for microbiological investigations.

\section{INVESTIGATIONS}

Samples taken with a platinum loop from the urethra and cervix were Gram stained to identify intracellular Gram negative diplococci and other organisms. For culture for Neisseria gonorrhoeae similar samples were plated directly on to a culture plate, one half of which consisted of blood agar and the other half modified New York City culture medium. These plates were incubated at $37^{\circ} \mathrm{C}$ in an atmosphere of $10 \% \quad \mathrm{CO}_{2}$. Material from the endocervix and urethra was taken on cotton wool swabs; one swab was stored in chlamydial transport medium and a second in herpes virus transport medium at $0^{\circ} \mathrm{C}$. Vaginal material was examined by culture for trichomonal and candidal infections. At the patient's initial visit cervical cytology was undertaken on all patients. A midstream specimen of urine was obtained for microscopy and for culture on MacConkey agar.

Patients whose urine bacterial count was $\geqslant 10^{5}$ were diagnosed as having a urinary tract infection. The leucocyte count in the urine was determined by calculating the mean number of cells in at least 10 microscopic fields $(\times 400)$. Chlamydia trachomatis was cultured on cytochalasin-B treated McCoy cell monolayers, Herpesvirus hominis (HVH) on 
fibroblast monolayer MRC-5 cells, and Trichomonas vaginalis and Candida spp on commercially available media (Oxoid). In each patient serological tests for syphilis and herpes complement fixation tests were performed. Paired sera were examined for herpes antibodies only if HVH was isolated in culture.

\section{TREATMENT}

The patients were treated according to the microbiological diagnosis. Oral metronidazole was given for trichomoniasis and topical clotrimazole for candidosis. Gonoccocal infection was treated with ampicillin in a $2 \mathrm{~g}$ oral dose with probenecid $1 \mathrm{~g}$ orally. Patients with chlamydial infections were treated with oxytetracycline or erythromycin by mouth $250 \mathrm{mg}$ four times a day for two weeks. The symptomatic patients in whom no microbiological cause was found were treated with oxytetracycline or erythromycin for seven days. Compliance with treatment was assessed by counting the tablets at the end of the course. All patients were advised to abstain from any sexual contact until they had attended the clinic for follow up. Microbiological tests of cure were carried out one week after treatment in all patients except those who were treated for chlamydial infection; in the last case the tests were performed two weeks after treatment.

\section{Results}

The mean age of the women was $24 \cdot 2$ years (range 15-43 years). Of the 107 patients, 92 were single or divorced and 83 used some form of contraception; 73 had had multiple sexual partners within the last three months.
A microbiological diagnosis was reached in most cases. Fifty eight women had $\geqslant 5$ polymorphonuclear leucocytes per high power field of urine. The most common cause of frequency and dysuria was gonorrhoea. $C$ trachomatis was isolated from the urethra of 12 of 25 women (table I). Eight patients had an Escherichia coli urinary tract infection. In four patients herpes virus was isolated from the cervix and urethra. Paired sera examined for a rising titre of complement fixing antibody to herpes was confirmed in only two of the infected patients. Organisms were not isolated from specimens collected from 13 patients with pyuria.

TABLE I Isolation of organisms from the cervix and urethra in women $\geqslant 5$ polymorphonuclear leucocytes per microscope field of urine

\begin{tabular}{llll}
\hline \multirow{2}{*}{$\begin{array}{l}\text { Microorganism } \\
\text { isolated }\end{array}$} & \multicolumn{3}{l}{ No of women harbouring organism in: } \\
\cline { 2 - 4 } & Cervix & Urethra & Cervix and urethra \\
\hline Neisseria gonorrhoeae & 21 & 19 & 19 \\
Chlamydia trachomatis & 17 & 12 & 12 \\
Herpesvirus hominis & 4 & 4 & 4
\end{tabular}

Forty nine patients had $<5$ pus cells per microscope field in their urine. Of these, 18 harboured Candida albicans, $12 T$ vaginalis, and two $C$ trachomatis in the urethra; no pathogenic microorganisms were isolated from material from 17 women.

Microbiological tests of cure were carried out at one week and two weeks after treatment. The results are shown in table II.

Of 30 patients who did not have microbial infection of the genitourinary tract, 22 attended the follow up clinic. Nineteen patients had total symptomatic relief. After tetracycline treatment for seven days 19 women were completely free of symptoms.

TABLE II Results of treatment in 107 patients

\begin{tabular}{|c|c|c|c|c|}
\hline \multirow[b]{2}{*}{ Diagnosis } & \multirow[b]{2}{*}{$\begin{array}{l}\text { No of patients } \\
\text { treated }\end{array}$} & \multirow[b]{2}{*}{ Treatment } & \multicolumn{2}{|c|}{ No of patients } \\
\hline & & & Cured & $\begin{array}{l}\text { Defaulted } \\
\text { at follow up }\end{array}$ \\
\hline Gonorrhoea & 16 & Ampicillin with probenecid & 16 & 0 \\
\hline $\begin{array}{l}\text { Gonorrhoea and chlamydial } \\
\text { infection }\end{array}$ & 5 & $\begin{array}{l}\text { Ampicillin with probenecid } \\
\text { and oxytetracycline }\end{array}$ & 5 & 0 \\
\hline Chlamydial infection & 14 & Oxytetracycline & 14 & 0 \\
\hline Escherichia coli infection & 8 & Co-trimoxazole & 8 & 0 \\
\hline Candidosis & 18 & Clotrimazole pessary and cream & 18 & $\mathbf{0}$ \\
\hline Trichomoniasis & 12 & Metronidazole & 12 & 0 \\
\hline Herpes genitalis & 4 & Hygiene only & $*$ & 0 \\
\hline No organism isolated & 30 & Oxytetracycline & + & 8 \\
\hline
\end{tabular}

*Some symptomatic relief

tRelief of symptoms in 19 patients 


\section{Discussion}

The causes of frequency and dysuria in women attending a sexually transmitted diseases clinic are entirely different from those seen in general practice. Gonorrhoea and chlamydial infections are the major causes of the syndrome in STD clinics and accountfor more than $30 \%$ of cases; $E$ coli is the commonest cause in general practice. ${ }^{3} 4$ In general practice, however, routine cultures for $N$ gonorrhoeae and $C$ trachomatis were not carried out. The availability of these tests has widened the microbiological spectrum of the urethral syndrome. The difference is also increased by self referral and referral by the family practitioner to the STD clinics.

$C$ trachomatis has previously been shown to be an important cause of the urethral syndrome in college girls in the United States. Stam et al ${ }^{5}$ suggested that girls with chlamydial infections had changed sexual partners often and used oral contraceptive methods. These findings were consistent with the sexual transmission of $C$ trachomatis in the chlamydial urethral syndrome. The present study indicates that chlamydial infection is an important cause of frequency and dysuria in women attending STD clinics in the United Kingdom.

The prevalence of chlamydial infection in women who attend STD clinics is about 20-30\%. ${ }^{9}$ Isolation rates are higher in women with consorts who have non-gonococcal urethritis. ${ }^{10} 11$ Chlamydial infection is also commonly associated with pelvic inflammatory disease, Bartholinitis, and neonatal conjunctivitis. ${ }^{7}$ The response to treatment is satisfactory. In the urethral syndrome it is important to investigate for both eubacterial and chlamydial infection.

The relief of symptoms after empirical tetracycline treatment suggests that in some cases the symptoms may have been due to tetracycline-sensitive organisms such as Mycoplasma spp and Gardnerella vaginalis, which were not identified in our investigations. ${ }^{12}$

I thank Professor A W Asscher of the department of renal medicine, Dr C H L Howell of the Public Health Laboratory Service, Dr J Munro of the department of virology, and Dr L Cohen of the department of genitourinary medicine for their help.

\section{References}

1. Waters EW, Elwood PC, Asscher AW, Abernethy M. Clinical significance of dysuria in women. Br Med J 1970;ii:754-7.

2. National Center for Health Statistics, Ambulatory medical care rendered in physicians' offices. United States, 1975; Adv Data 1977; 12:1-12.

3. Gallagher DJA, Montgomerie JZ, North JDK. Acute infection of the urinary tract and urethral syndrome in general practice. Br Med J 1965; i: 622-6.

4. Brookes D, Mauder A. Pathogenesis of urethral syndrome in women and its diagnosis in general practice. Lancet 1972; ii:893-8.

5. Stam WE, Wagner KF, Amsel R, et al. Causes of acute urethral syndrome in women. N Engl J Med 1980;303:409-15.

6. Tait A, Rees E, Jameson RM. Urethral syndrome associated with chlamydial infection of urethra and cervix. $\mathrm{Br} J$ Urol 1978;50:425.

7. Handsfield HH, Stam WE, Holmes KK. Public health implications and control of sexually transmitted chlamydial infections. Sex Transm Dis 1981;8:85-6.

8. Chang TW, Fiumara NJ, Weinstein L. Genital herpes: some clinical and laboratory observations. JAMA 1974;229:544-5.

9. Nayyar KC, O'Neil JJ, Hambling MH, Waugh MA. Isolation of Chlamydia trachomatis from women attending a clinic for sexually transmitted diseases. $B r J$ Vener Dis 1976;52:396-8.

10. Paavonen J. Chlamydia trachomatis induced urethritis in female partners of men with non-gonococcal urethritis. Sex Transm Dis 1979;6:69-71.

11. Weil A. Gaudenz R, Burgener L, Schultz B. Isolation of Chlamydia trachomatis from women with urethral syndrome. Arch Gynecol 1981; 230:329-33.

12. Stolz E, Nayyar KC. Corynebacterium vaginale infection. In: Harris JRW, ed. Recent advances in sexually transmitted diseases 1981:229-38. 